\title{
Reflections on reflections: mirror use in a university dance training environment
}

\author{
Shantel Ehrenberg
}

\begin{abstract}
This article explores aspects of the dancer-mirror relationship from the dancer's perspective and examines the various ways the mirror may impact on dancers' experiences in particular training environments. The essay foregrounds a small group of female university dance degree students' own words about training with and without mirrors in contemporary dance technique classes and considers their descriptions alongside the existing literature. Ethnographic-style interviews with six dancers were conducted and key themes which emerged upon analysis inform the essay. Although contemporary dance is the focus, content is applicable to other Western theatre dance styles and training environments.
\end{abstract}

Keywords: mirror, reflection, kinaesthesia, self-image, dance pedagogy

Mirror use in Western theatre dance training can be a topic which opens up rich dialogue about the complexity of dancers' kinaesthetic sensations and visual perceptions in training. Is the mirror as valuable or detrimental as is presumed in the training of dancers in university degree programmes in forms like ballet and contemporary? What layers of experience might emerge from dancers' discussions about dancing with and without mirrors in a specific context which build on and challenge the existing literature?

This essay explores these questions by weaving practical and theoretical literature with a small group of female university student dancers' descriptions about mirror use, adding the often silent dancers' voice to the discourse (Green and Stinson 1999). The impetus for this research was to explore the extent to which a dancer's visual perception of a mirror image might be intertwined with his/her kinaesthetic sensations. The dancer's embodied experiential duet with his/her projected dancing in the mirror is the focus of this essay. This is a conscious singling out of a particular type of kinaesthetic-visual reflection. It is acknowledged that reflection can manifest via many other interactions as well, such as with an audience, other dancers, touch, and music. 
1. Two texts claim mirror use started around this time, but precise historical references are not given: 'Ballet dancers, for example, have insisted on practicing before a mirror since the middle of the eighteenth century ...' (Foster 1997, p. 253). 'Since some time in the nineteenth century, the mirror has played an ever present partner to the ballet student and performer ...' (Bull 1997, p. 272).
2. In North America, generally the term 'modern dance' is still used to refer to Graham, Cunningham and release techniques; whereas in Europe 'contemporary' is more common.
3. Also known as Cynthia Jean Cohen Bull.
Mirror use in Western theatre dance training has a relatively undocumented history, with no definitive references to be found in the literature specifying when dance training and the mirror became relatively synonymous. The prevailing idea is that mirror use began with ballet, probably around the late eighteenth century when mirror technology was rapidly developing and mirrors were popular in the homes of European aristocrats. ${ }^{1}$ Modern dance, as it arose in the early 1900s, most likely adopted (or rejected) the tradition of mirror use from ballet.

\section{Method}

Six female undergraduate dancers, in the second year of a university dance degree programme, volunteered to be interviewed for this project. The dancers' ages ranged from 19 to 22. They were all enrolled in the same upper-level contemporary technique class. Interviews were conducted after four consecutive classes, two with mirrors and two without. Institutional Review Board (IRB) approval was received for this study. An ethnographicstyle methodology was used, considering the university dance classroom as one locus of dance culture and dancers' communicated experiences as interpretive description (Novack 1990, Chiseri-Strater and Sunstein 1997, Green and Stinson 1999, Mason 2002). The methodological assumption for this research was similar to socio-constructivism as expressed by Fortin et al. (2002, p. 156), namely that the dancers' "'truth" is linked to their experience and as such their voice is a construction of their reality'. Questions were semi-structured with the freedom to go off-course according to dancer responses (Spradley 1979) and the situated and contextual aspects of the interview were considered (Mason 2002). Interviews were transcribed, given to the dancers for feedback and analysed. Observation of dance classes and a small survey were also a part of the research. Though a contemporary dance class was used as the setting, other Western theatre dance styles, such as ballet and jazz, were discussed.

\section{University dance training and mirrors}

Contemporary dance training is a central part of many university dance degree programmes. ${ }^{2}$ Contemporary dance technique is a particularly fruitful context to explore mirror use (or non-use) because of the general emphasis on the internal kinaesthetic experience, though it is also a performed art which is watched by an outside eye. A number of texts discuss the ever-oscillating emphasis and approach to the internal kinaesthetic from early modern to current contemporary dance practices. Elizabeth Dempster (1995), for instance, reports that early modern dances were based on emotional and psychological imperatives - the governing logic was not pictorial, as in ballet, but affective. Dee Reynolds (2007) writes at length about the shifting uses of kinaesthetic energy in the works of Wigman, Graham, and Cunningham. Cynthia Novack ${ }^{3}$ (1990, p. 135) states that with postmodern dance there was a move away from 'presenting an (artificial) 
image' and the importance was to present 'a real, or authentic' way of moving.

Despite a focus on the internal kinaesthetic experience in contemporary technique, the existing literature, dancer interviews for this research, and the author's 15 years' experience in dance supported the argument that the mirror is still a part of many university dance training environments. As one dancer interviewed for this project put it, 'I think [the mirror] is just part of our culture as dancers ... it's such a normal thing for us ...' One reason for this continued use of mirrors, particularly in university dance programmes, may be that, as dance scholar Susan Foster (1997, p. 253) argues, dancers training to be professionals today need to be well-versed in a number of styles and be 'multitalented' dancers. Hence, the mirror may be present so that the institution can accommodate a number of techniques and teacher preferences, all under the same degree programme with specific building and budgetary constraints.

\section{Mirror as tool}

The mirror is generally considered useful as a tool. Several dancers interviewed supported this claim. One dancer said, "With the mirror it is good to see my placement ... sometimes I look at the mirror and see I am doing a movement wrong, I need to fix my sway back, or whether my flat back was as it should be.' Another dancer supported the usefulness of the mirror for knee alignment: 'I use the mirror for self-correction in contemporary class in the very beginning when I am trying to find parallel, because my feet want to do this [shows turning in], and my knees want to do this [shows feet going in counter direction], so just to get that down.' 'Sometimes the mirror is nice to have', another dancer said, 'such as when a teacher corrects me and she says I am doing something incorrectly and I don't feel it, and then I look in the mirror and am very surprised at what I see ... sometimes I need to look in the mirror to feel it.'

Several authors echo the dancers' statements about the mirror as tool. The mirror is said to be useful, from a motor control and learning perspective, for basic body alignment, such as seeing the height of a limb, relationships between body parts, correct or incorrect positions, and/or help teachers observe students while demonstrating (Kimmerle and CôtéLaurence 2003). As Lynch et al. (2009, p. 289) point out, it is often assumed in dance (and also Pilates, martial arts, and weight rooms) that mirrors provide immediate visual feedback which will help motor skill learning. Dearborn and Ross (2006), in one of several experimental studies, found that a group of college dancers who learned with a mirror had better retention of movement over a two-week period than a group that learned without a mirror. Legrand and Ravn (2009, p. 404), using ethnographic and phenomenological methodologies, report that a group of contemporary dancers said they do not commonly use the mirror but if they do, they use it 'to supplement their experience of how a quality of movement sensed from within the body is visible on the surface, in the changing shapes of the body'. 
4. Maurice Merleau-Ponty's (1964, p. 129) critique of Lacan's mirror stage is also relevant here, but unable to be fully addressed in this essay. The child looking in the mirror, he writes, 'must displace the mirror image, bringing it from the apparent or virtual place it occupies in the depth of the mirror back to himself, whom he identifies at a distance with his introceptive body' (also cited in Weiss 1999, p. 12).

\section{Dancer-mirror feedback loop}

The dancer statements and literature relating to the mirror as tool pointed to a functional back and forth pattern between dancers' kinaesthetic sensations and visual perceptions. This pattern is useful to present as a preliminary model within a complex web of dancers' expressed relations with the mirror. The pattern includes two variables: a dancer's visually perceived image in the mirror and a dancer's kinaesthetically sensed feeling of his/her body. Upon analysis, the mirror image and the dancer's kinaesthetic awareness were consistently affecting each other in a cyclical action-reaction pattern, thus this process was termed the dancer-mirror feedback loop.

An example of the dancer-mirror feedback loop goes something like: dancer sees his/her shoulders close to ears in mirror image, dancer directs kinaesthetic awareness to shoulders, dancer moves shoulders away from ears, dancer looks at new position in mirror image, and so on. There is a general process described as 'look and feel and look', which is then broken up into specific parts, such as, 'look at image, feel incorrect alignment, adjust body, look at image again, re-feel correction', etc. The feedback loop was particularly evident when dancers did a tendu combination in front of a full length mirror as part of the interviews. One of the dancer's during this exercise said, 'I was doing the tendu and I felt my ankle wiggle and so I looked at it and I realized that it wasn't in alignment and I needed to change that.' Philosopher Timo Klemola (1991, p. 14) describes the dancer-mirror relationship as a back and forth process between subject and object, 'the dancer moves from the lived body to the objective body through a mirror and back again to the lived body and from there again back to the objective body through a mirror, etc.'. Anthropologist Gail Hall (1977, p. 205) describes it as a 'tacit conversation', stating that the reflexive evaluation of the body through the mirror of disdain or approval is repeated so quickly that action and reflection seem to occur simultaneously for the dancer.

The dancer-mirror feedback loop may be envisioned in the way feminist scholar Elizabeth Grosz (1994, p. xii) describes Lacan's Möbius strip: 'The Möbius strip has the advantage of showing the inflection of mind into body and body into mind, the ways in which, through a kind of twisting or inversion, one side becomes another'. Dance scholar Sylvie Fortin uses the same metaphor related to dance experience 'to demonstrate how a twist in the band allows a fluid exchange of self to other, inner to outer' (as cited in Jackson 2005, p. 30). Grosz (1994, p. xii) notes that this model also provides a way of problematizing and rethinking the relations between the inside and the outside of the subject ... by showing ... the torsion of the one into the other' (addressed further below). ${ }^{4}$

Holmes and Spence (2006, p. 23) contend, from the cognitive science point of view, that extended experience with mirrors enables us to process the reverse image of ourselves quickly and there is a significant plasticity in the sensorimotor system in relationship to mirrors. They point out that the existence of mirror agnosia signals a specific neural function for making mirror-image transformations. The identification of so-called mirror neurons in neuroscience (e.g. Gallese et al. 1996), in which it is hypothesised that humans have similar neural responses when watching as when doing related 
movements, has inspired a shift in fundamental beliefs about the interactions of action and perception. Mirror neurons are interesting to mention briefly for the potential relationship with the concept of a dancer-mirror feedback loop. In particular, the discovery of mirror neurons has spurred neuroscientists to explore how dance expertise affects what dancers see, particularly those movements with which dancers demonstrate motor and visual expertise (e.g. Calvo-Merino et al. 2005). Though speculative, the dancer-mirror feedback loop involves an interchange, for the dancer, between what movement kinaesthetically feels like (motor action neurons) and what movement looks like (visual perceptual neurons), in ways which distinctly relate to the functioning of the so-called mirror neuron system as it is currently conceived. The dancer-mirror feedback loop may nurture a particular type of motor-visual coupling for the dancer regarding his/her own dancing.

'It's a useful tool, BUT ...'

In the above descriptions the mirror is said to aid dancers' learning and selfcorrection abilities. On the other hand, these descriptions inspire other questions and concerns not unfamiliar to dance practitioners. Indeed, the most common response during the research, from both participants and in conversation with colleagues, was: 'the mirror is a useful tool, BUT...' The simultaneous apprehension about mirror use signalled contradictory themes and challenged any straightforward analysis of this group of dancers' experiences with mirrors in training.

\section{Dys-function of dancer-mirror feedback loop}

Some dys-functional aspects of the dancer-mirror feedback loop were discussed in direct contrast to the mirror as a useful tool. For instance, several dancers interviewed described self-correction using the mirror initially, but then difficulty retaining that correction kinaesthetically. As one dancer described it, 'I end up correcting [a misalignment] by sight [in the mirror] and then I end up going back to how it was before, eventually...'

Results from empirical research support the argument that mirrors do not necessarily enhance motor control and learning of dance skills. For instance, Radell et al. (2004) found that a group of university-level dancers who learned without a mirror (over a 14-week ballet course) performed better in an adagio phrase at the end of the study than a group that trained with a mirror.

The mirror has been criticised for over-emphasis on shape and body parts, void of the qualities of motion, speed and space, which can impact on dancers' performance (Cheney 1989). Freelance writer Jen Jones (2008) writes that visual mirror distractions take away from developing a certain performance quality and the mirror might be used to rely on other dancers to remember choreography. Dance educator Jan Erkert (2003) writes that the mirror gives an inaccurate reflection that does not represent the threedimensional person. Foster (1997, p. 238) states that the mirror might be at 
5. For other uses of imagery in dance technique, see also Nordin and Cumming (2006). times like 'the demonstrative body' which 'isolates moments in a movement sequence or parts of the body in order to present an analysis of the ideal'.

Several of the dancers' descriptions supported the claim that the mirror presents a static body rather than a three-dimensional body in motion. As one dancer described it, 'I don't think the mirror helps me understand how my body moves because the mirror shows static images ... I just find the mirror distracting; it takes my brain away from my body.' Another dancer said, 'I focus on small details of parts and lines [of the body] and I do not think about what my whole body is doing.' One dancer described spatial body sensations, 'The mirror gives me the frontal view and I am bombarded with that and I cannot concentrate on the energy that is going out through the crown of my head or through my temples, the sides and periphery of my body.' Another student talked about flow and texture, in contrast,

I think that is what it is when the mirror is gone. I have to think about how my muscles look and feel inside my body and how my body is oriented within so that I can get a flow of the movement. When the mirror is there I lose this flow. I am concentrating more on the texture of my body, how my body is reacting in the space and how that looks, as opposed to the texture of the movement ... how the movement feels.

Authors have argued mirror use might prevent students from developing kinaesthetic awareness and/or trusting their proprioceptive sense because the two-dimensional visual image can dominate dancers' perceptual attention (Kimmerle and Côté-Laurence 2003, pp. 196-197, Montero 2006). Some practitioners have focused on enhancing kinaesthetic awareness by merging somatic practices (e.g. Alexander, Feldenkrais, Body-Mind Centring) and dance training (Fortin et al. 2002, Jackson 2005). Application of somatics to contemporary dance training has been said to facilitate re-patterning and dynamic bodily awareness specific to one's own way of moving, using distinct exercises, verbal cues, and tactile feedback in contrast to instigating change via feedback from an externalised image (Fortin et al. 2002, Claid 2006). Internalised metaphoric imagery is sometimes used in lieu of an external image. For example, Eric Franklin (1996) describes using the image of the pelvis as a bouncing ball in jumps to help stabilise the centre and yet retain the feeling of lift and rebound. ${ }^{5}$ The application of somatics to dance technique has not been solely functional, however, and can be seen to relate to concerns in feminist theory as well (addressed below).

Dancers said their ability to use imagined images was affected by the actual images in the mirror. One dancer described the mirror as giving too much visual information:

It is easier for me to focus without a mirror in the dance class, without so much distraction. In the mirror you see all the students, other objects, and such in the reflection of the room. When there is a blank wall, on the other hand, it's like a blank slate. I can imagine stuff, imagine something there instead.

Another dancer said, 'I can't get past my own image when the mirror is there. When the mirror is not there I can feel free to think about whatever I want and concentrate on how it feels.' 
6. Cases of phantom limb raise questions about misrepresentation via proprioception. Indeed this research was inspired by a case study in which a man is able to sense movement of a previously immobile phantom limb by looking at a mirror image of his opposite arm in motion (Ramachandran and Blakeslee 1998).
Philosopher Barbara Montero (2006, p. 232) argues that proprioception might be conceived of as an aesthetic sense. She argues that professional dancers 'seem to experience aesthetic qualities proprioceptively and make aesthetic judgements based, at least in part, on proprioceptive experience'. She also notes that proprioception, like vision and the illusion in the mirror, can also misrepresent. For instance, a leg can feel straight even though it is bent. There is plasticity to kinaesthetic awareness, as was hinted to with findings in the aforementioned cognitive science studies. ${ }^{6}$

\section{The inner critic}

There was evidence of an inner critic in expressions from dancers when talking about the mirror as tool. One dancer illustrated her personal struggle with the mirror and indicated the critical eye was of most concern:

\footnotetext{
There are times in contemporary when we do not use the mirror and I don't know what I look like but it feels good. But at other times I will use the mirror and the movement still feels good to me. I use the mirror as a useful focus point. So I don't really know, I think the mirror helps me but at the same time I think it helps to be away from the mirror. Sometimes I unhelpfully find myself being critical with the mirror.
}

Feminist theory is particularly relevant to this research, not only because all participants were women, but this is an important factor. Eluned SummersBremmer (2000, p. 101) argues, for instance, that women may be more likely than men to attach to an objectification and failure of the mirror image:

To attempt an unbridgeable gulf between ideal and reality, mind's eye and movement, is psychologically distressing because it fails, and yet, attachment to failure is a kind of satisfaction to which women ... may be culturally predisposed to lay claim)

Gail Weiss (1999, p. 47) likewise writes that '“feminine" bodily existence' is problematic when the imaginary others (i.e. mirror reflection) can dominate and supersede women's own experiences of their bodily capacities, which she relates to Lacan's mirror stage and the desire to be the object of another's desire. The split subject arises, she argues in discussion of Iris Marion Young's work, because women internalise aspects of a patriarchal social system and overcoming this split subject involves overcoming 'the invisible and omnipresent male gaze' (ibid., p. 50). Scholars writing about dance have noted a number of relationships between feminist theory, contemporary dance aesthetics, and the privileging of the visual (e.g. Thomas 1996). Writing specifically about the mirror, dance scholar Jill Green (2003, p. 112) (also reporting on a group of university dance students' experiences in training) argues that one of the ways some pedagogical approaches '[aim] to achieve normative behaviour' is through the use of mirrors. Participants in her research, similar to the dancers in this study, made reference to mirrors 'as an ominous and powerful presence that contributed to physical self-evaluation, behavior regulation, body objectification, and competition' 
(ibid., p. 112). Along the same lines, Claid (2006, p. 81) writes that letting go of the mirror is a 'rejection of the desire to be the beautiful image and all the paraphernalia that comes with external praise ....'. Daily staring in the mirror (as might be done with repeated exposure), others argue, might lead to narcissistic tendencies or a troublesome body image (Erkert 2003, Oliver 2008).

Several dancers interviewed talked about the mirror as gazing critic and as instigator of a certain anxiety in line with feminist critiques of the visual. One dancer noticed a change with mirror absence: 'I felt relieved when we didn't have the mirror, not even knowing that I felt relieved because once we opened the curtains and I could see the mirror, I got anxious and I realized how relieved I was with the curtains closed.' Another dancer put it this way: 'I think that in order to dance well I have to dance confidently, and sometimes I am more insecure when I am looking at myself [in the mirror].' One dancer talked about the comparative aspects:

When facing away from the mirror in class one day, I noticed that I felt freer to do what I want because there was no one else's eyes looking back at me and I could not see anyone else, I did not care what anyone was thinking about me ... as soon as we turned away from the mirror it didn't feel like I had any criticism from anyone else, I guess. Even though the criticism from my peers might not be there, facing the mirror I can feel like it is.

One dancer indirectly associated the mirror with a demand for perfection, '[When the mirror was covered] I was able to just move and understand the combinations without making them perfect.'

In parallel to some of the above perspectives in dance and feminist theory, an empirical study with a sample of sedentary young women (non-dancers) found the mirror had a negative impact on participants' 'feeling states'. Ginis et al. (2003, p. 359) found that those who exercised for 20 minutes on a stationary bicycle in front of a mirror had 'primarily negative outcomes - a decrease in positive engagement, a tendency toward decreased tranquility, no change in physical exhaustion, and only a small increase in revitalization'. Related to this, the mirror might be seen to encourage extrinsic (versus intrinsic) motivation, as is theorised in dance psychology research, and thus increased risk for dropout, negative affect, diminished self-esteem and feelings of autonomy (Quested and Duda 2009).

\section{Embodying values}

The dancers' discussions about the mirror reflected independent analysis of its use across varying training and performance contexts. As one dancer put it:

As an older dancer, in all genres, I find that a lot of times I do not look in the mirror except if something is facing forward and I need a sense of the look and feel of the movement. In particular, here at university for contemporary dance it is a distinct type of training, I am taking class every day and the performance is the class, not in preparation for a performance per se. 
Another dancer said,

I find the mirror helpful for ballet, where the line is really important and there are things you can correct quickly and the orientation is frontal, but in contemporary I find it is more enjoyable to not use the mirror and just feel the movement and there are multiple directions in space to move within.

The dancers indicate that the mirror may represent varying values across dance styles taught in the university setting. It may be necessary to look at detail in the mirror when working toward a performance, for instance, or when techniques are more codified, such as with ballet or Graham. But in other approaches to dance training, such as release technique or those related to somatic practices, the mirror may serve less of a purpose because of the greater emphasis on internal kinaesthetic examination. Foster (1997, p. 236) scrutinises dance technique values as they relate to the 'theatrical dancer as a body-of-ideas'. She writes about ways that dance techniques, such as Cunningham and contact improvisation, 'constructs a specialized and specific body' (ibid., p. 241). The choice such as whether or not to use a mirror in dance techniques, she argues, 'introduces students to the set of metaphors out of which their own perceived and ideal bodies come to be constructed' (ibid., p. 253).

A few dancers made comments related to their teachers that resonated with an intentional move away from a pictorial ideal in the mirror and an embodiment of certain ideologies. One dancer said, 'Contemporary dance teachers always tell you not to look in the mirror ... to more feel it, not to really depend on what you look like and make it more what you feel like. Even if we are facing a mirror, teachers tell me to have a focus "outside" or "beyond" the mirror.' Another dancer talked about a sense of agency in dance technique,

My current contemporary dance teacher takes the focus away from her and makes me think about stuff while I am moving and I feel like that has helped me feel the movement more in my body, her class has helped me take more responsibility for all sorts of things, such as how I am feeling a particular day, whether I am really tired, what I eat and so on. I feel I have to make choices in class, such as where I am going to go in space, and I can make choices from my perspective instead of 'what would the teacher want me to do?'

A few of the dancers indicated they view the mirror differently over time: 'Since I have started dancing I have gotten more and more comfortable with my body, looking at it' and 'I find that I do not use the mirror that much anymore, at the university level of training.'

On this last point the literature is notably inconclusive about when mirrors should be used in training. Gretchen Ward Warren, in Classical Ballet Technique (1989), states that the mirror is a crucially important tool for expert dancers to assess and readjust their body line. Kimmerle and CôtéLaurence (2003, pp. 196-197) write that the 'skilled learner' or 'experienced dancer' should be able to monitor their performance internally, therefore 'no longer requiring extrinsic feedback from .... the mirror' and beginning dancers may find correct alignment when using the mirror. Dance journalist Richard Merz (1991) advises that the mirror's reflection of only outer 
appearance may instil a sense of shame in young people. Julia Buckroyd (2000), from her experience as a dance counsellor, writes that it is unlikely the teenage student is capable of seeing an accurate mirror image or detaching him/herself from what s/he sees in the mirror.

\section{Constructing dancing self-images}

Dancers' experiences with mirrors in the context of university training are loaded, contradictory, and multi-layered. Jaana Parviainen, author of Bodies Moving and Moved (1998), writes about the complicated relationship for the dancer and his/her external image, one that is both me yet not me. In line with Merleau-Ponty and several authors cited above, she writes that there is a limited perspective through 'the other' in the mirror, an incessant escaping. Yet it is through these gaps and conflicts that the professional dancer in training constructs him/herself as a performer, Parviainen 1998, p. 73 writes:

In order that the other can reflect an image of myself, I must learn to find a communion with otherness and a reciprocity through which I can identify myself, while I can also learn about otherness, since I am fundamentally a limited embodied perspective. There is an incessant escaping between me as I feel myself and me as I see myself. Furthermore, there is an 'incessant escaping' between me and the other: how I see myself and how the other defines me, which produces conflicts between me and the other... But through those conflicts I can locate and admit the crucial difference between me and the other, constructing my own identity. (Parviainen 1998, p. 73)

There are both positive and negative aspects to the dancer's reflected self-image, as found in the comments presented; sometimes dancers like using the mirror and other times it is distinctly unnerving. The mirror may prepare dancers for performance and being perceived, watched, and judged by others. Merleau Ponty (1964, p. 136) writes, for example,

the image in the mirror prepares me for another still more serious alienation, which will be the alienation by others. For others have only an exterior image of me, which is analogous to the one seen in the mirror. Consequently others will tear me away from my own immediate inwardness much more surely than will the mirror.

The mirror might remind a dancer that his/her dancing is perceived through some eye, some lens. Denial of the mirror image as instigating a 'false' sense of self might also ignore that there is no 'real' self - only a self through different lenses. Parviainen (1998, p. 72) also writes:

The mirror image itself makes possible contemplation of the self. The human body is sensible to itself, but also it is unknown to itself, since the self also contains otherness (Dillon 1988, 9). Because our relation to ourselves is not one of sheer coincidence but contains otherness, we must also simultaneously 
speak of personal identity and difference ... The other is a mirror to me, it reflects and it may distort what I am.

Similar to Legrand and Ravn's (2009, p. 400) investigation, the dancers in this study 'constantly erode the distinction between sensing from the outside and sensing from the inside of the body. They both externalize inside sensing and internalize the external eye'. The distinctions to be made from the dancer's perspective between kinaesthetic feeling ('self') and being viewed by a teacher, choreographer, audience ('other') continually blur.

\section{Conclusion}

Discussion with a small group of dancers about using and not using the mirror in contemporary dance training at the university level supported the argument that the mirror and dancers' experience with it are paradoxical and full of intriguing links with dance studies and other disciplines, such as phenomenology, cognitive science, and feminist theory. This essay could only skim the surface of a wealth of complex issues which emerged from the interviews and the literature.

There is on the one side an unavoidable interlinking between kinaesthetic sensations and visual perceptions in dancer experience, particularly in consideration of the performative aspects of being a dancer. The mirror image presents to the dancer one type of visual representation of his/her kinaesthetically felt movement which at times aids self-correction and performance accuracy. On the other side, however, are various negative connotations with the mirror, particularly the occasional failure of correction via an external image, negative effects on performance quality, critical appraisal and comparison with an unattainable ideal. This group of dancers indicated they actively analysed these contrasting aspects of the mirror and considered its use in some contexts and not others.

What needs further consideration is a dancer's complex relationship with the projected image of his/her dancing as a performer. In the case of the dancers in this research, there were not only two sides to the reflection, but layers upon layers of intricate interpretations of the mirror image and indication that reflection (of all kinds) was important to these dancers as they aspire to become professionals. This group of dancers' described experiences related to mirrors were multi-faceted. The mirror cannot be relegated as a device which impacts on dancers' experiences that are simply good or bad, objective or subjective; instead what appears is a web of co-existing, even when contradictory, interpretations which expose the many roles the mirror plays for this group of dancers. Dancers in training should be further supported to interrogate and critically analyse what they see and feel with their dancing mirrored reflections, questioning from all sides prevailing assumptions about mirror use/non-use in dance training (as should be the case with all modes of feedback). Just as other forms of technology are being investigated increasingly in university dance programmes, such as motion capture and interactive video, the mirror is also a type of technology offering up (sometimes by its contrasting absence) explorative possibilities of various modes of being. The real 

Ehrenberg S. (2010) 'Reflections on reflections: mirror use in a university dance training environment'. Theatre, Dance and Performance Training, $1(2)$, pp. 172-184.

challenge is left with the dancer, who must continually negotiate multiple connections between feeling and projecting his/her dancing to an outside eye, learning how to play with the many illusory aspects of being a dance performer.

\section{Acknowledgements}

Thank you to the dancers who participated in this study with openness and generosity. I am indebted to Professor Jennifer Fisher for her invaluable supervision and guidance with this research, and Professor Dee Reynolds, for her supervision in my current doctoral work which helped revisit this essay. I extend gratitude to two anonymous reviewers for their generous feedback on this manuscript.

The research presented formed part of the author's MFA thesis (Ehrenberg 2005). This work was first presented at the International Association for Dance Medicine \& Science (IADMS) conference, Stockholm, Sweden, November 2005, http://www.iadms.org.

\section{References}

Buckroyd, J., 2000. The Student Dancer: Emotional Aspects of the Teaching and Learning of Dance. London: Dance Books.

Bull, C.J.C., 1997. Sense, Meaning, and Perception in Three Dance Cultures. In: J.C. Desmond, ed. Meaning in Motion. Durham, NC: Duke University Press, 269-287.

Calvo-Merino, B., et al., 2005. Action Observation and Acquired Motor Skills: An fMRI Study with Expert Dancers. Cerebral Cortex, 15 (8), 1243-1249.

Cheney, G., 1989. Basic Concepts in Modern Dance. Pennington, NJ: Princeton Book Co.

Chiseri-Strater, E. and Sunstein, B.S., 1997. Field Working: Reading and Writing Research. Upper Saddle River, New Jersey: Prentice-Hall Inc.

Claid, E., 2006. Yes? No! Maybe .... Seductive ambiguity in dance. London: Routledge.

Dearborn, K. and Ross, R., 2006. Dance Learning and the Mirror: Comparison Study of Dance Phrase Learning With and Without Mirrors. American Journal of Health Education, 6 (4), 109-115.

Dempster, E., 1995. Women Writing the Body: Let's Watch a Little How She Dances. In: E.W. Goellner and J.S. Murphy, eds. Bodies of the Text. New Brunswick, New Jersey: Rutgers University Press, 21-38.

Ehrenberg, S., 2005. Reflections on Reflections: Modern Dance and Mirror Use in a University Dance Training Environment. Unpublished thesis (MFA). University of California, Irvine.

Erkert, J., 2003. Harnessing the Wind: The Art of Teaching Modern Dance. Illinois: Human Kinetics.

Fortin, S., Long, W. and Lord, M., 2002. Three Voices: Researching how Somatic Education Informs Contemporary Dance Technique Class. Research in Dance Education, 3 (2), 155-179.

Foster, S.L., 1997. Dancing bodies. In: J.C. Desmond, ed. Meaning in Motion. Durham, NC: Duke University Press, 235-257.

Franklin, E., 1996. Dance Imagery for Technique and Performance. Champaign, IL: Human Kinetics.

Gallese, V., Fadiga, L., Fogassi, L. and Rizzolatti, G., 1996. Action Recognition in the Premotor Cortex. Brain, 119, 593-609.

Ginis, K.A.M., Jung, M.E. and Gauvin, L., 2003. To See or Not to See: The Effects of Exercising in Mirrored Environments on Sedentary Women's Feeling States and Selfefficacy. Health Psychology, 22, 354-361. 
Green, J., 2003. Foucault and the Training of Docile Bodies in Dance Education. The Journal of the Arts and Learning Special Interest Group of the American Education Research Association, 19 (1), 99-125.

Green, J. and Stinson, S.W., 1999. Postpositivist Research in Dance. In: S. H. Fraleigh and

P. Hanstein, eds. Researching Dance. Pittsburgh: University of Pittsburgh Press. Grosz, E., 1994. Volatile Bodies: Toward a Corporeal Feminism. Bloomington and Indianapolis: Indiana University Press.

Hall, G.A., 1977. Workshop for a Ballerina: An Exercise in Professional Socialization. Urban Life, 6 (2), 193-220.

Holmes, N.P. and Spence, C., 2006. Beyond the Body Schema: Visual, Prosthetic, and Technological Contributions to Bodily Perception and Awareness. In: G. Knoblich, I.M. Thornton, M. Grosjean and M. Shiffrar, eds. Human Body Perception from the Inside Out. Oxford: Oxford University Press, 15-64.

Jackson, J., 2005. My Dance and the Ideal Body: Looking at Ballet Practice from the Inside Out. Research in Dance Education, 6 (1/2), 25-40.

Jones, J., 2008. August. No Peeking. Dance Teacher, 30 (8), 100-102.

Kimmerle, M. and Côté-Laurence, P., 2003. Teaching Dance Skills: A Motor Learning and Development Approach. Andover, New Jersey: J. Michael Ryan Publishing, Inc.

Klemola, T., 1991. Frame Look and Movement: The Phenomenology of Dance. Ballet International (February), 13-14.

Legrand, D. and Ravn, S., 2009. Perceiving Subjectivity in Bodily Movement: The Case of Dancers. Phenomenology and Cognitive Science, 8, 389-408.

Lynch, J.A., Chalmers, G.R., Knutzen, K.M. and Martin, L.T., 2009. Effect of Performance of Learning a Pilates Skill With or Without a Mirror. Journal of Bodywork and Movement Therapies, 13, 283-290.

Mason, J., 2002. Qualitative Researching. London: SAGE Publications Ltd.

Merleau-Ponty, M., 1964. The Child's Relation with Others. Trans. W. Cobb. In: J.M. Edie, ed. The Primacy of Perception. Evanston: Northwestern University Press, 96-155.

Merz, R., 1991. 'Mirror, Mirror on the Wall...' Narcissism as a Dancer for the Art of Dance? Ballet International (June), 13-16.

Montero, B., 2006. Proprioception as an Aesthetic Sense. The Journal of Aesthetics and Art Criticism, 64 (2), 231-242.

Nordin, S.M. and Cumming, J., 2006. The Development of Imagery in Dance. The Journal of Dance Medicine \& Science, $10(1 / 2), 21-27$.

Novack, C.J., 1990. Sharing the Dance: Contact Improvisation and American Culture. Madison: The University of Wisconsin Press.

Oliver, W., 2008. Body Image in the Dance Class. Journal of Physical Education, Recreation and Dance, 79 (5), 18-25.

Parviainen, J., 1998. Bodies Moving and Moved. Tampere: Tampere University Press.

Quested, E. and Duda, J.L., 2009. Setting the Stage: Social-Environmental and Motivational Predictors of Optimal Training Experiences. Performance Research, 14 (2), 36-45.

Radell, S.A., Adame, D.D. and Cole, S.P., 2004. The Impact of Mirrors on Body Image and Classroom Performance in Female College Ballet Dancers. Journal of Dance Medicine \& Science, 8 (2), 47-52.

Ramachandran, V.S. and Blakeslee, S., 1998. Phantoms in the Brain: Probing the Mysteries of the Human Mind. New York: HarperCollins Publishers, Inc.

Reynolds, D., 2007. Rhythmic Subjects. Alton, Hampshire: Dance Books.

Spradley, J.P., 1979. The Ethnographic Interview. New York: Holt, Rinehart and Winston.

Summers-Bremner, E., 2000. Reading Irigaray, Dancing. Hypatia, 15 (1), 90-124. Available from http://muse.jhu.edu/journals/hypatia/v015/15.1summers-bremner.html

Thomas, H., 1996. Do You Want to Join the Dance? In: G. Morris, ed. Moving Words: Re-writing Dance. London and New York: Routledge.

Warren, G.W., 1989. Classical Ballet Technique. Tampa: University of State Florida Press.

Weiss, G., 1999. Body images: embodiment as intercorporeality. New York, NY and London, UK: Routledge. 